\title{
ThE UsE OF BALly-VALENS-REHAB SHOES TO IMPROVE GAIT IN Patients Following STROKe
}

\begin{abstract}
A randomised study was conducted to determine the influence which the Bally-Valens-Rehab shoes may have on gait in patients following stroke. The 11 subjects were all independent ambulators who were more than one year post stroke. Measurements were performed twice in opposite order to balance order effects. The reli-

\section{JAN KOOL, MSC, PT'; P OESCH, PT U SLOKSNATH, PT; O KNUSEL, MD}

'Rheuma- und Rehabilitationzentrum Valens, Switzertand ability of the measurements was good $(r>0.97)$. With the Bally-Valens-Rehab shoes, velocity improved by $8,6 \%$ from an average of 0.59 to an average of $0,64 \mathrm{~m} / \mathrm{s}(p=0.021)$. Step-length gained $6,2 \%(42,1 \mathrm{~cm}$ to $44,5 \mathrm{~cm}, p=0.026)$ and endurance improved from 119 to $126 \mathrm{~m} / 3$ minutes $(p=0.016)$. Meanwhile, ground reaction forces revealed a decrease in lateral force indicating a narrower, more normal gait $(p=0.059)$. The anterior-posterior force increased significantly $(p=0.021)$ showing that the shoes enhance heel-rise. The measurements confirmed the subjective findings and showed that use of the Bally-Valens-Rehab shoes in stroke patients may improve gait and enhance rehabilitation.
\end{abstract}

\section{INTRODUCTION}

Many patients with central neurological movement disorders use Bally-ValensRehab shoes because they feel that they walk better with these shoes (Gamper 1988). The study reported now was performed to answer the question whether this subjective feeling is accompanied by objectively measurable advantages.

In patients with increased tone following a stroke, paresis and loss of coordination reduce walking capacity (Rose and Gamble 1993). Stride length (2 successive steps $=1$ stride) decreases before cadence when walking speed is reduced. The base width becomes broader and the gait becomes asymmetrical, the duration of stance on the sound leg becoming relatively increased. The movement pattern during gait is influenced by many factors. Changing the shoes or orthosis in patients with hemiplegia immediately influences the gait pattern (Lehmann et al, 1987). During the stance phase the rocking movement of the involved foot is reduced, the knee may hyperextend before mid-stance or may show excessive flexion and the hip usually shows a

\section{CORRESPONDENCE:}

Jan Kool

Rheuma- und Rehabilitationszentrum

Valens

Switzerland

Email:kool.klival@spin.ch

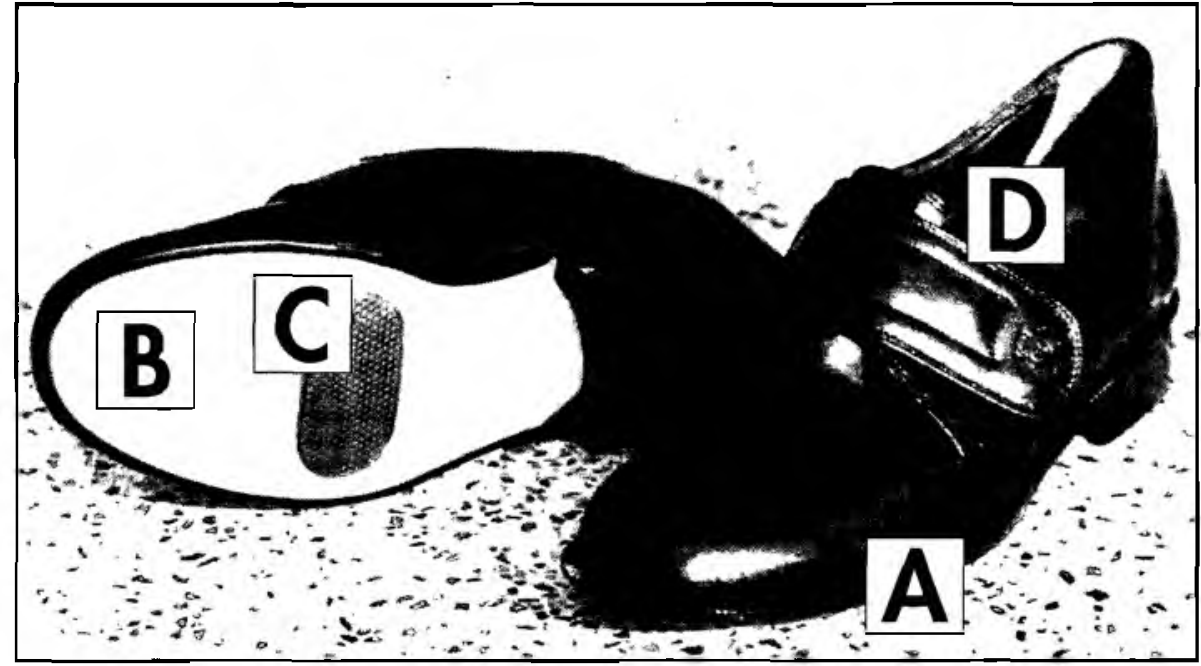

Figure 1: Bally-Valens-Rehab improve gail and at the mean time look like normal shoes. The shoes have a forefool rocker $(A)$ positioned dorsally to reduce activity of the toe flexors during stance and to facilitate heel off after mid stance. The forefoot leather sole $(B)$ reduces toe drag during swing. The non slip inlay $(C)$ in the forefoot sole give a secure stance. The firm and high support of the rear foot $(D)$ prevents supination during swing.

marked lack of extension. Some patients show a "stiff-legged" gait caused by lack of antagonistic coordination. At toe-off, knee extension activity is not "switched off' quickly enough. Circumduction and elevation of the pelvis on the advanced side during limb advancement may be caused by lack of selective movement at the hip or by insufficient dorsiflexion of the foot (Olney et al, 1991).

The Bally-Valens-Rehab shoe (Fig I) was developed to give the foot good support during stance and to facilitate heel-off by an integrated forefoot rocker, positioned $2 \mathrm{~cm}$ proximal to the normal position. The forefoot is thus lifted more than normally in order to inhibit the toe flexors. The forefoot sole is made of leather to reduce toe drag during swing, but stance security is enhanced by a non-slip inlay in the forefoot sole. The calcaneus has a special, extra high support to reduce supination during swing. Putting on the 
shoes one-handed is easy because of the velcro fastening. Bally-Valens-Rehab shoes look like normal shoes, which is an important advantage for the patient.

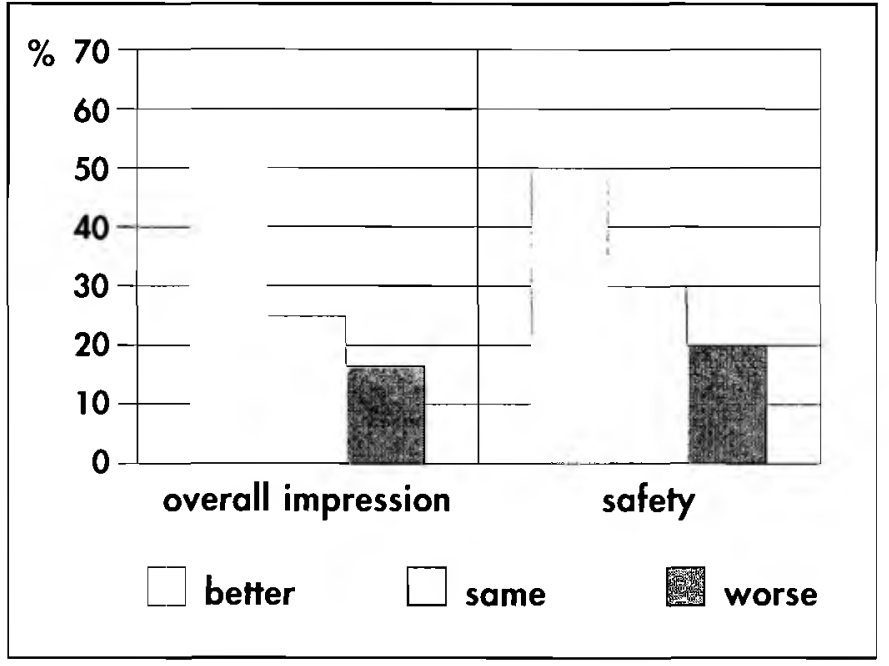

Figure 2: Patients judgement of the Bally-Valens-Rehab shoes showing a positive overall impression in $58 \%$ and in safety in $50 \%$ of the patients ( $n=65$, Gamper 1988).

In the study by Gamper (1988) $50-58 \%$ of the 65 patients gave a positive judgement on overall impression and safety of the Bally-Valens-Rehab shoes as compared with regular offthe-shelf shoes from a shop (Fig 2). In some cases the patient had worn these shoes before the stroke. Therapists observed and compared gait with two different types of shoes (Fig 3). An improvement was found in stride (25\%), supination (43\%), rhythm $(46 \%)$, heel contact $(64 \%)$ and toe-drag $(66 \%)$. These results showed that the shoe did not solve the problems of each and every patient.

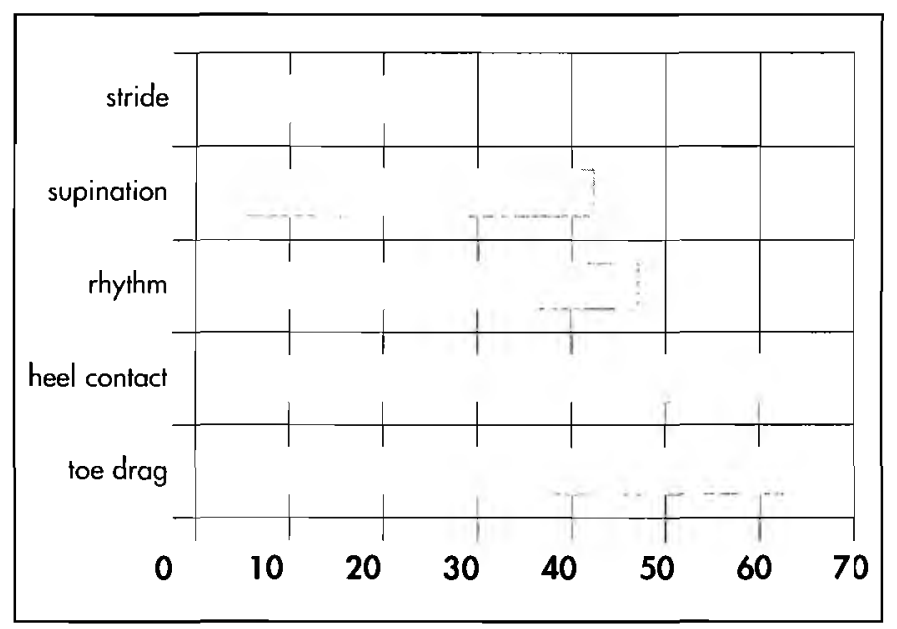

Figure 3: Therapists judgement of the Bally-Valens-Rehab shoes ( $n=65$, Gamper, 1988). An improvement was found in stride $(25 \%)$, supination (43\%), rhythm (46\%), heel contact (64\%) and toe drag $(66 \%)$

It has not been investigated whether the subjective improvement in gait noted by therapists and patients correlates with objective measures. To answer this question, a study was performed in a group of patients who in daily life regularly use Bally-Valens-Rehab shoes as well as regular shoes.
An almost infinite number of measurements can be performed in gait laboratories. Comfortable walking speed is generally considered the most important single measure (Wade et al, 1992). It correlates well with independence in activities of daily living (ADL) and with quality of life. Electromyography, angle- and force-measurements give information about the reasons for specific gait patterns.

In the observational judgement of the Bally-Valens-Rehab shoes (Gamper 1988) the reliability of the observations was not established. This was an important motivation for the present study, which also had the objective of determining which measurements are sensitive and valid in detecting clinically important differences in gait when special shoes are compared with regular shoes. These considerations led to the formulation of the following two questions:

\section{Do Bally-Valens-Rehab shoes positively influence}

- comfortable walking speed, stride length and endurance?

- ground reaction forces?

- flexion-extension movement at the hip- and knee-joint?

2. Which of the measurements used is the most sensitive to detect a meaningful difference between walking conditions?

\section{METHOD}

\section{$A$ randomised and balanced design}

Walking with Bally-Valens-Rehab shoes (A) and regular shoes (B) was compared. The measurements under the second condition could be positively influenced by practice or negatively influenced by fatigue. In order to eliminate this possible source of bias, all measurements were carried out twice. The first series of measurements was done in the morning, the second in the afternoon. Randomisation determined the shoes in which the first series of measurements was taken. The second series of measurements was performed in reverse order to balance order effects and prevent bias. The resulting measurement order was either ABBA or BAAB.

\section{Subjects}

The population consisted of all stroke patients treated in three rehabilitation centres in Switzerland (Valens, Zihlschlacht and Braunwald) from $1992-1994$. The inclusion criteria were as follows:

- Patients with a first, supratentorial, unilateral CVA

- Independent walking with both Bally Valens-Rehab and regular shoes

- Canes and orthoses were accepted provided that they were used with both types of shoe.

Patients were excluded if their walking capacity was negatively influenced by co-morbidity (heart disease, orthopaedic problems, reduced vision or hearing).

Written information about the aim and conditions of the study was sent to all patients considered for participation. Persons who signed and returned the informed consent form were contacted by the researcher to discuss further questions, check the admission criteria and make an appointment for the measurements. 


\section{Measurements}

The reliability (reproduceability and precision) of the instruments used depends strongly on the study population. We therefore did not rely on reliability established in other studies and determined the reliability for the studied group.

\section{Walking speed, stride length and endurance}

Comfortable walking speed and stride length were measured on a 25 meter walkway. Patients were instructed to walk the trajectory at their normal comfortable speed. They were not aware of the fact that the number of steps was counted. Endurance was measured by asking the patient to walk as far as possible in three minutes. At 1,2 and $2^{1 / 2}$ minutes the patients were informed of the time that had passed. The researcher was at all times at a distance of 2 metres from the patient.

The validity of these measurements is generally accepted. An increased gait velocity correlates with greater independence in ADL (Collen et al, 1991), a smaller risk of falling (Wolfson et al, 1990) and a more normal gait pattern (Richards et al, 1996). Walking speed has a good sensitivity to change, which is a requirement for this study of gait in different types of shoes. In a randomised cross-over study by Wade et al (1992) walking speed significantly increased after a three-week treatment.

\section{Goit andysis}

We registered joint angles and ground reaction forces on a walkway 12 metres long, 1.2 meters broad and $4 \mathrm{~cm}$ high. The patient was instructed to walk at his or her comfortable speed. Videorecordings were made at the mean time and several trials were needed before the individual starting point was found from where the force-plate was hit squarely. The patients were not informed of the need to strike the forceplate because this might have changed the gait pattern.

\section{- Ground reaction force measurements} Ground reaction force was measured at a rate of $250 \mathrm{~Hz}$ with a $40 \times 60 \mathrm{~cm}$ force-plate (Kistler AG, CH-Winterthur, Switzerland), filtered (Bioware, Kistler AG) and converted (analogue-digital). Time was expressed in \% contact. The average of 10 measurements was used for interpretation.

\section{- Angle measurements}

Two-dimensional measurements of flexion and extension at the hip and knee joints were recorded with the Postural Locomotion System (Qualisys, Sweden) and the MacReflex 2D Motion Analysis System, consisting of an infrared camera with integrated infrared flashlight. The camera records the marker at the lateral malleolus, the knee and the greater trochanter at a frequency of $50 \mathrm{~Hz}$. The video processor computes two-dimensional coordinates from the camera data. The MacIntosh IIci computer and Walk-Watcher Software allows further analysis (Kesselring et al, 1992). The reliability of these measurements has been established in an earlier study (Oesch et al, 1995). Generally the variation in range of motion between trials (gait cycles) is greater than the measurement error of the equipment (Nigg et al, 1994).

\section{Questionnoire}

All patients were asked for their opinion about Bally-Valens-Rehab shoes compared with normal shoes regarding safety during walking, maximal walking distance, toe drag, supination of the foot, spasticity in general, comfort for the toes, ease in putting the shoes on and off and the appearance of the shoes.

\section{RESIIITS}

\section{Recruitment}

Information about the study was sent to 75 patients and 33 were interested in participation. After checking the admission criteria by telephone, an appointment for the measurements was made with 12 patients. One patient was excluded because she used a different type of Bally shoe. The results thus relate to 11 patients (Table 1).

\section{TABLE 1}

\begin{tabular}{|l|l|}
\hline Age, mean (SD) & 64 years (SD 5 years) \\
\hline Sex & 10 men, 1 woman \\
\hline Time since stroke, median (range) & 2,8 years (12 months - 8 years) \\
\hline Side of lesion & 2 left, 9 right \\
\hline Ankle foot orthosis & $\begin{array}{l}1 \text { patient used the same orthosis } \\
\text { in both shoes }\end{array}$ \\
\hline Cane & 2 patients \\
\hline
\end{tabular}

\section{Walking speed, stride length and endurance}

The reliability of the measurements of walking speed, stride length and endurance were very good, with a Pearsons r of greater than .98 for all measurements (Table 2). The average percentage difference between repeated measures (precision) was between 3 and $13 \%$.

\section{TABLE 2}

\begin{tabular}{|l|cc|cc|}
\hline \multicolumn{1}{|c|}{ Clinical test } & \multicolumn{2}{|c|}{ Correlation } & \multicolumn{2}{c|}{$\begin{array}{c}\text { Precision } \\
\text { (average \% difference, 95\% BI) }\end{array}$} \\
& Bally & Normal & Bally & Normal \\
\hline Walking speed $\mathrm{m} / \mathrm{s}$ & .99 & .98 & $4,0 \%(1,5-6,4 \%)$ & $13,3 \%(7,8-18,8 \%)$ \\
\hline Stride length $\mathrm{cm}$ & .99 & .99 & $3,3 \%(1,3-5,4 \%)$ & $9,4 \%(6,1-12,6 \%)$ \\
\hline Endurance $\mathrm{m} / 3 \mathrm{~min}$ & .99 & .99 & $4,6 \%(2,7-8,2 \%)$ & $4,9 \%(2,4-11,4 \%)$ \\
\hline
\end{tabular}

Table 3 shows the results of the clinical gait measurements. Statistical testing of the differences was done using the students t-test. Walking velocity with Bally-ValensRehab shoes was $8,6 \%$ (range $1,6 \%-21,2 \%$ ) greater than with regular shoes. This difference was statistically significant $(\mathrm{p}=0,02)$ Stride length was significantly greater with Bally-Valens-Rehab shoes, at $89,0 \mathrm{~cm}$ as compared with $84,2 \mathrm{~cm}$ for regular shoes - a difference of $2,4 \mathrm{~cm}$ or $6,2 \%(\mathrm{p}=0,026)$. Endurance was also significantly greater in Bally-Valens-Rehab shoes, patients walking 6,3\% further in three minutes. 
TABLE 3

\begin{tabular}{|c|c|c|c|}
\hline $\begin{array}{l}\text { Clinical test } \\
\text { Walking speed }\end{array}$ & $\begin{array}{c}\text { Normal shoes } \\
\text { (mean, SD, range) } \\
\mathbf{0 , 5 9} \mathrm{m} / \mathrm{s} \\
\text { SD } 0,23 \mathrm{~m} / \mathrm{s} \\
\text { range } 0,21-1,01 \mathrm{~m} / \mathrm{s}\end{array}$ & $\begin{array}{c}\text { Bally-Valens } \\
\text { (mean, SD, range) } \\
0,64 \mathrm{~m} / \mathrm{s} \\
\text { SD } 0,22 \mathrm{~m} / \mathrm{s} \\
\text { range } 0,27-0,99 \mathrm{~m} / \mathrm{s}\end{array}$ & $\begin{array}{c}\text { Difference } \\
\begin{array}{c}\text { (\%, SD, p-value) } \\
+8,6 \% \\
\text { SD } 8,4 \% \\
\mathrm{p}=0,021\end{array}\end{array}$ \\
\hline Stride length & $\begin{array}{c}42,1 \mathrm{~cm} \\
\mathrm{SD} 11,8 \mathrm{~cm} \\
\text { range } 14,8-54,4 \mathrm{~cm}\end{array}$ & $\begin{array}{c}44,5 \mathrm{~cm} \\
\text { SD } 11,4 \mathrm{~cm} \\
\text { range } 14,8-54,4 \mathrm{~cm}\end{array}$ & $\begin{array}{l}+6,2 \% \\
S D 7,0 \% \\
p=0,026\end{array}$ \\
\hline Endurance & $\begin{array}{c}118,8 \mathrm{~m} / 3 \mathrm{~min} \\
\text { SD } 52,8 \mathrm{~m} \\
\text { range } 39,2-207,0 \mathrm{~m}\end{array}$ & $\begin{array}{c}126,3 \mathrm{~m} / 3 \mathrm{~min} \\
\mathrm{SD} 53,2 \mathrm{~m} \\
\text { range } 48,7-224,5 \mathrm{~m}\end{array}$ & $\begin{array}{l}+6,3 \% \\
\text { SD 7,9\% } \\
p=0,016\end{array}$ \\
\hline
\end{tabular}

\section{Ground reaction forces}

After normalisation of the 10 measurements with both the Bally-ValensRehab shoes and the regular shoes, average curves were made. The maximal vertical force Fy was equal with both types of shoe. The lateral force $\mathrm{Fz}$ and the forward-backward force $F x$ were expressed relative to the vertical force Fy to correct for the influence of difference in walking speed and the resulting difference in average total force. The average forward force Fx was significantly greater with Bally-Valens-Rehab shoes $(p=0,021)$. From heel-contact until mid-stance the decelerating force was smaller, whereas the accelerating force from mid-stance until toe-off was greater with Bally-Valens-Rehab shoes (Fig.4)

The average lateral force was smaller with Bally-Valens-Rehab shoes, but this difference did not reach significance $(\mathrm{p}=0,059)$.

\section{Angle measurements}

To determine the reliability of the knee and hip flexion-extension measurements we determined the standard deviation of repeated measures, which was on average 1,5 degrees. There were no differences in knee and hip range of motion for the total group when walking with BallyValens-Rehab shoes and walking with regular shoes were compared.

\section{Questionnaire}

Safety during walking with BallyValens-Rehab shoes was judged better by 8 of the 11 patients. Seven patients reported that they could walk a longer distance with Bally-Valens-Rehab shoes and 8 mentioned reduced toe-drag as an advantage. Six patients gave a negative judgement of the appearance of the Bally-Valens-Rehab shoes.

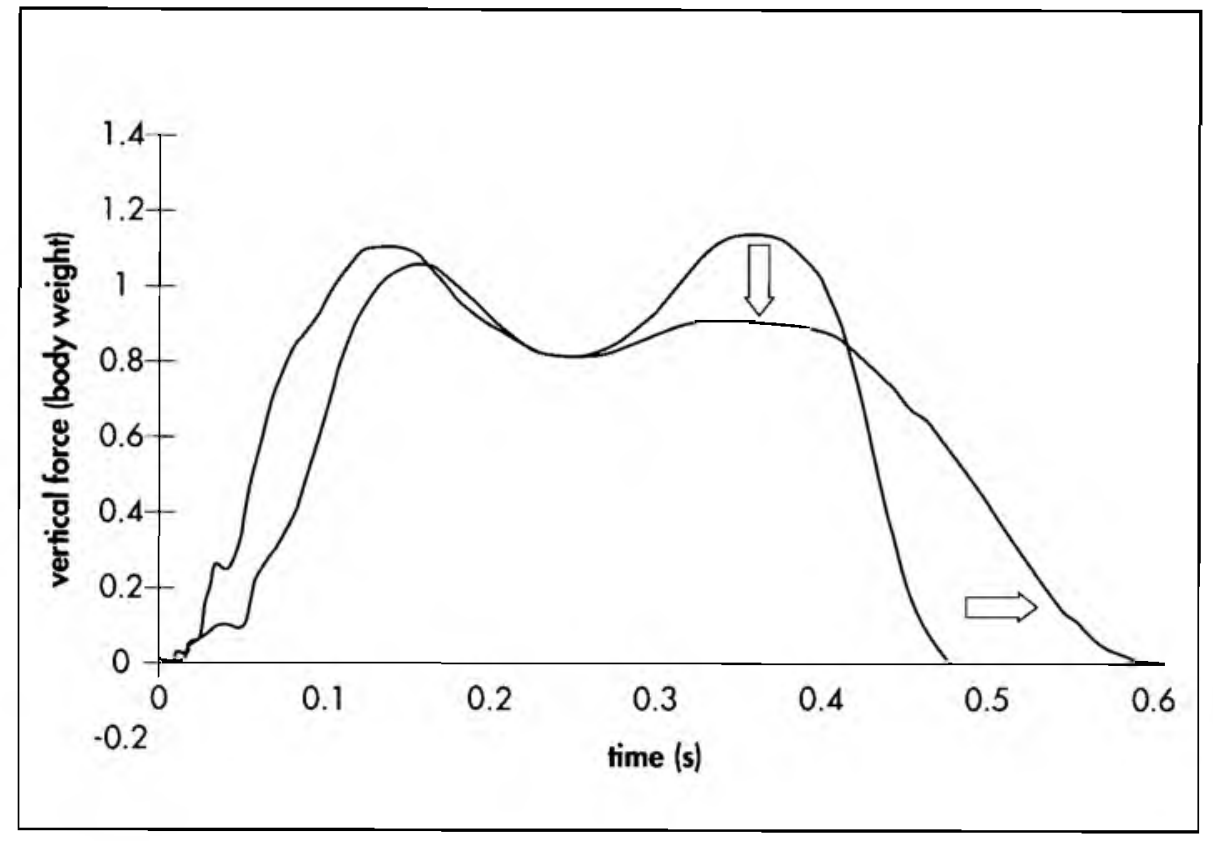

Figure 4: Bally-Valens-Rehab shoes increase the net forward force by reducing the decelerating force and increasing the accelerating force.

\section{DISCUSSION}

Walking speed is obviously reduced in the studied group of patients $(0,59 \mathrm{~m} / \mathrm{s})$ as compared with that of healthy persons $(1,2 \mathrm{~m} / \mathrm{s})$. The average step length is $0,42 \mathrm{~m}$ in hemiplegic patients and $0,67 \mathrm{~m}$ in healthy elderly persons (Waters et al, 1989). Considering this limitation of walking capacity, an improvement of $8,6 \%$ is substantial for many patients.

In a healthy population, Nigg measured ground reaction forces with different normal and standard shoes (Nigg et al, 1994). The difference between shoes was inconsistent and minimal $(<1,3 \%)$. The consistent and significant difference in the current study is thus of considerable clinical importance. The improvement in propulsion with Bally-Valens-Rehab shoes is comparable with the effect of an ankle-foot orthosis in other studies (Lehmann et al, 1987). Patients show a marked reduction of lateral weight transfer towards the involved side following stroke, as well as in propulsion. Both these problems were reduced by the use of Bally-Valens-Rehab shoes.

Our results concerning reliability are in accordance with Nigg, who showed that the measurement of walking velocity showed the best reliability, followed by force measurements, with angle measurements in the last place.

The negative results of the angle measurements need some consideration. Joint movements during walking depend strongly upon walking speed and leg length. Age alone has little influence on joint movements, but older people walk more slowly (Oeberg et al, 1994). The importance of speed can be illustrated 
by the following measurements. The total range of flexion and extension in the hip joint is on average $55^{\circ}$ at a walking speed of $1,5 \mathrm{~m} / \mathrm{s}$, reducing to $35^{\circ}$ at $0,5 \mathrm{~m} / \mathrm{s}$. For the knee joint the speed related difference is much smaller $-63^{\circ}$ at $1,5 \mathrm{~m} / \mathrm{s}$ and $58^{\circ}$ at $05, \mathrm{~m} / \mathrm{s}$. In our population of patients who have suffered a stroke and who had an average walking speed of $<0,5 \mathrm{~m} / \mathrm{s}$, the range of flexion and extension was even smaller than expected from the above-mentioned normal values for slow walking. The negative results of the angle measurements may result from at least two factors. The poor reliability of angle measurements is one. The other is that patients show deviations in opposite directions from the normal movement during gait. In a patient with pronounced hyperextension of the knee during stance, a reduction of the degree of extension during the stance phase is an improvement. When the knee is in too much flexion during stance, an increase in extension is desirable.

Gamper's (1988) results of systematic patient interviews and observations by therapists showed subjective advantages for using Bally-Valens-Rehab shoes.
The subjective results of this study are similar. Only the appearance of the shoe was judged negatively by a majority of one, which is understandable as no variety of shoes designs are available to suit individual preferences.

The improvement in walking speed, stride length, endurance and force measurements confirm the earlier subjective findings. The magnitude of the differences measured when using BallyValens-Rehab shoes is similar to that found by Lehman et al (1993) in a study demonstrating the positive effect of ankle-foot orthoses.

\section{CONCLUSIONS}

Although the use of the shoe may have a placebo effect due to the advice and opinions previously received from other professionals (therapist, orthopaedic technician, doctor) the results of this study demonstrate the positive influence of the Bally-Valens-Rehab shoe on the walking capacity of patients following stroke.

The first research question concerned the influence of the Bally-Valens-Rehab shoe on walking capacity, and significant differences in walking speed, stride length and endurance were found. These differences are clinically significant. Gait analysis gave further information about the underlying mechanisms for this improvement. The increased net forward force indicates that the rocking movement of the foot is improved. The decrease in relative lateral force demonstrates that the base becomes narrower because the body weight is transferred better onto the involved leg. These findings support the subjective impressions of the patients. Flexion-extension movements of the hip and knee showed no changes, possibly as a result of varying gait deviations between patients.

The second question was to determine which of the measurements used is most sensitive in detecting a clinically meaningful difference. For this purpose it has been shown that a high-tech gait laboratory is not necessary. Recording walking speed and stride length on a 25 meter walkway has the greatest sensitivity to change and is available to every therapist. By using this in conjunction with the patient's subjective judgement, a clinical decision regarding the most appropriate footwear is easy to make. $\square$

\section{REFERENCES}

Collen, F. M., D. T. Wade, et al. (1991) The Rivermead Mobility Index: a further development of the Rivermead Motor Assessment. Int Disabil Stud 13(2): 50-54.

Gamper, U. (1988) Ein neues Schuhkonzept für Hirngeschädigte. Der Physiotherapeut(3): 2-8.

Kesselring, J., C. Calame, et al. (1992) Ganganalyse- eine Voraussetzung für eine allgemeine Bewegungsanalyse. Schweiz Rundschau Med 81(49): 1495-1499.

Lehmann, J. F. (1993) Push-off and propulsion of the body in normal and abnormal gait. Correction by ankle-foot orthoses. Clin Orthop 288: 97-108.

Lehmann, J. F., S. M. Condon, et al. (1987) Gait abnormalities in hemiplegia: their correction by ankle-foot orthoses. Arch Phys Med Rehabil 68(1I): 763-771.
Nigg, B. M., V. Fisher, et al. (1994) Gait characteristics as a function of age and gender. Gait and Posture 2: 213-220.

Oeberg, T., A. Karsznia, el al. (1994) Joint angle parameters in gait: Reference data for normal subjects, 10-79 years of age. Journal of Rehabilitation Research and Development 3I(3): 199-213

Oesch, P. und J. Kesselring (1995) Bewegungsmessung in der Neurorehabilitation. Neurol Rehabil 1: 30-35.

Olney, S. J., M. P. Griffin, et al. (1991) Work and power in gait of stroke patients. Arch Phys Med Rehabil 72: 309314.

Richards, C. L. and Olney, S. J. (1996) Hemiplegic gail following stroke. Part II: recovery and physical therapy. Gait and Posture 4: 149 162.
Rose, J. and J. G. Gamble (1993) Human Walking. Baltimore, Williams and Wilkins.

Wade, D. T., F. M. Collen, et al. (1992) Measurement in neurological rehabilitation. New York, Oxford University Press.

Wade, D. T., F. M. Collen, et al. (1992) Physiotherapy intervention late after stroke and mobility. British Medical Journal 304 (7 March): 609-613.

Waters, R. L. und J. S. Yakura (1989) The energy expenditure of normal and pathological gait. Crit Rev in Phys Med Reh 1: 183195.

Wolfson, L., R. Whipple, et al. (1990) Gait assessment in the elderly: a gait abnormality rating scale and its relation to falls. J Gerontol 45(1): M12-M19. 